\title{
POSTO REVENDEDOR DE COMBUSTÍVEIS: VERIFICAÇÃO QUALITATIVA DA VULNERABILIDADE E RISCO SOCIOAMBIENTAL À CIRCUNVIZINHANÇA
}

\author{
Antônio Pereira Júnior; Laryssa Passos Brandão;_Sandreane dos Santos Ribeiro \\ DOI: $10.4322 / 978-85-455202-1-4-04$ \\ INTRODUÇÃO
}

No Brasil, o conceito legal de meio ambiente encontra-se disposto no art. $3^{\circ}$, I, da Lei Federal $n^{\circ}$. 6.938:1981, que dispõe sobre a Política Nacional do Meio Ambiente: "o conjunto de condições, leis, influências e interações de ordem física, química e biológica, que permite, abriga e rege a vida em todas as suas formas". O meio ambiente constitui um dos temas essenciais das políticas governamentais e uma das maiores preocupações dos cidadãos, seja nos países industrializados ou não. Pois, com o crescente processo de industrialização verificado desde o final do século XX, ao lado do incremento das pesquisas, do desenvolvimento e da difusão de novas tecnologias, os processos de produção e seus respectivos produtos, têm contribuído para pôr em perigo ou causar prejuízos à saúde humana e ambiental (SOUZA, 2009).

Nesse contexto, meio ambiente é definido como a circunvizinhança em que uma organização opera, incluindo-se ar, água, solo, recursos naturais, flora, fauna, seres humanos e suas inter-relações. Uma organização é responsável pelo meio ambiente que a cerca, devendo, portanto, respeitá-lo, agir como não poluente e cumprir as legislações e normas pertinentes. Os PRC se distribuem nos centros urbanos, no meio rural e nas estradas (rodovias), esta atividade é encontrada nos mais diferentes locais, independente do porte das atividades econômicas realizadas na região e representam ainda hoje uma importante atividade para a economia nacional. Essas atividades são bastante diversificadas e envolvem não só o abastecimento, mas também troca de óleo e lavagem de veículo, loja de conveniência, lanchonete, restaurante, etc. (ISO 14001:2004; SANTOS, 2005; SOUZA, 2009).

Tal atividade é considerada como uma das fontes mais importante de contaminação do ar dos grandes centros urbanos, através dos produtos derivados do petróleo, como o óleo diesel e a gasolina. A qualidade do ar nas atividades de revenda e abastecimento de combustíveis líquido tem sido motivo de preocupação em todo mundo, especialmente nas grandes metrópoles, uma vez que essas atividades apresentam um alto risco para os trabalhadores locais, clientes e às pessoas que transitam diariamente pelas vizinhanças ou até mesmo residem nas imediações (SANTOS, 2014).

Em razão disso, o Estudo de Impacto de Vizinhança (EIV) é um documento focado na análise de impactos à qualidade de vida urbana, na vizinhança do empreendimento e o Estudo Prévio de Impacto Ambiental (EPIA) é voltado aos impactos causados ao meio físico, biótico e socioeconômico. Um impacto à vizinhança também é um impacto ambiental, mas nem todo impacto ambiental é um impacto à vizinhança.

A caracterização da vizinhança pode ser efetuada através do Diagnóstico Ambiental, pois, nele, se identifica a Área Diretamente Afetada (ADA) pelo empreendimento, bem como o entorno imediato, o que deverá compor a Área de Influência Direta (AID). Essas áreas deverão ser estabelecidas pela equipe responsável pela execução do estudo, que deverá considerar como ADA, aquela submetida diretamente às intervenções necessárias à implantação do empreendimento, e como AID, aquela sujeita aos impactos diretos, decorrentes da implantação e operação do empreendimento. Sua delimitação deverá ser feita em função das características dos meios físico, biótico e antrópico e das particularidades do projeto (IBAMA, 2007).

Em razão disso, faz-se necessário classificar o uso do solo para identificar as unidades presentes na ADA e AID, com o auxílio da Lei Municipal nº 17.213:2006 que institui o Plano Diretor 
Participativo (PDP) do Município de Marabá, cria o Conselho Gestor do Plano Diretor e dá outras providências:

Unidade Residencial: aquele destinado à moradia unifamiliar ou multifamiliar, segundo os parâmetros urbanísticos definidos nos quadros que integram a presente lei.

Unidade Não-residencial: aquele destinado ao exercício de uma ou mais das seguintes atividades (industrial, comercial, de prestação de serviços e institucional).

Unidade Mista: aquela constituída pelos uso-residencial e não-residencial na mesma edificação.

Por sua vez, essa classificação auxilia no levantamento de dados quanto ao uso e ocupação do solo no entorno do empreendimento, com a finalidade de identificação da população vulnerável, que são: trabalhadores do posto, trabalhadores eventuais e moradores da vizinhança.

\section{VULNERABILIDADE, RISCO E PERIGO}

Os conceitos sobre vulnerabilidade são normalmente compreendidos como a suscetibilidade física, política ou social de um sistema ou comunidade a um dano, quando sujeito a uma perturbação ou pressão ambiental, ao invés de medida de um dano real, ou seja, em uma definição lata, é o potencial para perda. A vulnerabilidade inclui elemento de exposição ao risco (as circunstâncias que colocam as pessoas e as localidades em risco perante um determinado período), de propensão (as circunstâncias que aumentam ou reduzem a capacidade da população, da infraestrutura ou dos sistemas físicos para responder e recuperar de ameaças ambientais). Essas definições tão simples e genéricas apreendem a essência da vulnerabilidade (CUTTER, 2011; GALLOPIN, 2006),

Contudo, sabe-se que, esse conceito é atrelado a um ou mais fatores provocadores da vulnerabilidade: exposição, sensibilidade e resiliência. $\mathrm{O}$ estudo desses fatores permite a avaliação da maior ou menor vulnerabilidade de um sistema a determinadas questões ambientais. Dessa forma, um sistema é mais vulnerável quanto maior as pressões e a sensibilidade do meio e menor sua capacidade adaptativa (). Nesse contexto, com maior ou menor importância, a vulnerabilidade está sempre presente e, por conseguinte, o risco também. A vulnerabilidade é intrínseca à noção de risco, que é conceituado como a probabilidade de que um evento, esperado ou não esperado, se torne realidade. A ideia de que algo pode vir a ocorrer, já configura um risco. É importante ressaltar que a vulnerabilidade opera apenas quando o risco está presente; sem risco, vulnerabilidade não tem efeito (ADGER, 2006; JANCZURA, 2012; PELLETIER, 2007).

Quanto ao risco, a Occupational Health and Safety Assessment Services (OHSAS), normativa 18001:1999, o define como a "combinação da frequência, ou probabilidade, e das consequências da ocorrência de uma situação de perigo específica”. Destaca-se que o conceito de perigo difere do risco, pois, àquele tem as características elencadas de uma atividade ou substância, que podem causar algum tipo de dano para pessoas, instalações ou meio ambiente (LIMA; COSTA JÚNIOR; BACELAR NETO, 2008).

Em relação à análise do conceito de risco e vulnerabilidade pode-se inferir que independentemente das palavras utilizadas, é aceito por quase todos os que se dedicam a este tipo de estudos, que o risco é, então, o somatório de algo que nada tem a ver com a vontade do homem (aleatório, acaso, casualidade ou periculosidade), com algo que resulta da presença direta ou indireta do homem, ou seja, a vulnerabilidade (). Ainda sobre o risco, é conveniente estabelecer o conceito de iminente, pois é a ameaça de se concretizar, ou seja, que está a ponto de acontecer, próximo, imediato. O risco iminente é o risco que pode ocorrer, porém não há como afirmar quando vai ocorrer; isto é, um tipo de evento inesperado que ocorre no ambiente (DAGNINO; CARPI JUNIOR, 2007; HOUAISS, 2001).

Contudo, ao associar as tipologias de risco e vulnerabilidade do local em que se encontra a população diretamente afetada, a vulnerabilidade pode ser delineada, identificando o risco e as medidas preventivas que podem ser tomadas para diminuí-lo ao máximo, minimizando a vulnerabilidade. Por outro lado, faz parte de uma pesquisa considerar as formas como a sociedade 
poderá e deverá reagir para absorver e recuperar-se do impacto do perigo, caso este se realize (MARANDOLA JUNIOR; HOGAN, 2006a).

Nesse contexto, o risco ambiental é a probabilidade condicional de ocorrer um evento com repercussões ambientais específicas (impactos ambientais) como: contaminação de um corpo d'água; contaminação do solo; redução da biodiversidade e perda de recursos comerciais importantes. Tal risco é função de vários fatores, como: natureza do perigo; possibilidade de contato (potencial de exposição); possibilidade de ocorrência do evento indesejado; magnitude da exposição e das consequências (impactos), bem como da existência de valores públicos importantes. Quanto à tipologia dos riscos a serem abordadas sabe-se que os ambientais resultam da associação entre os riscos naturais e os riscos decorrentes de processos naturais agravados pela atividade humana e pela ocupação do território (CUNHA, 2008; VEYRET; RICHEMOND, 2007).

Em função disso, o risco ambiental remete à possibilidade de ocorrência de eventos danosos ao ambiente, enquanto que, para a legislação que trata de licenciamento, a noção de impacto ambiental está ligada à repetição de algo que já aconteceu e que poderá significar um evento positivo ou negativo, podendo comprometer a licença para instalar um empreendimento em determinado local. Vale ressaltar que os riscos ambientais estão ligados tanto a agentes físicos e químicos, quanto a biológicos que tendem a impactar os ecossistemas circunvizinhos quando ultrapassam os limites do ambiente de trabalho, podendo atingir os compartimentos ambientais (solo, ar e água). Também podem estar associados a vazamentos, extravasamentos, transbordos e emissões, entre outros. Os mesmos tornam-se riscos reais quando ultrapassam os limites das normativas cabíveis e quando afetam a saúde ambiental e humana. Pode-se relacionar também como riscos ao meio ambiente os fenômenos da natureza como enchentes, inundações e alagamentos (DAGNINO; CARPI JUNIOR, 2007; RIELLI, 2007).

Outro tipo de risco é o risco social, que representa risco para um grupo de pessoas constituído pela comunidade exposta aos efeitos dos acidentes passíveis de ocorrer nas instalações em análise. Assim, o risco social diz respeito à população presente na zona de alcance dos efeitos físicos gerados pelos diferentes cenários de acidentes. Como se observa, risco é sempre um objeto social, seja quando uma comunidade ou indivíduo específico são atingidos, vivenciam ou sofrem com um risco natural ou telúrico que, de certa forma, independe de suas ações diretas; assim, o homem é o centro do nosso interesse (FARIAS, 2010; IELO; ZACHARIAS, 2014).

Todavia, pode-se correlacionar os conceitos de risco e perigo, como: o risco sendo a probabilidade de perigo, geralmente com ameaça física para o homem e/ou para o meio ambiente; isto é, um evento ou ato que possui consequências adversas. Além disso, se apresenta em situações ou áreas em que existe a probabilidade, susceptibilidade, vulnerabilidade, acaso ou azar de ocorrer algum tipo de ameaça, perigo, problema, impacto ou desastre (MARANDOLA JÚNIOR; HOGAN, 2006b).

Contudo, os termos perigo (hazard) e risco (risk) são frequentemente utilizados como sinônimos, mas não o são. O perigo é um fenômeno natural que ocorre em épocas e regiões conhecidas que podem causar sérios danos nas áreas sob impacto. Assim, perigos naturais (natural hazards) são processos ou fenômenos naturais que ocorrem na biosfera, podendo constituir um evento danoso e serem modificados pela atividade humana, tais como a degradação do ambiente e urbanização. Enquanto que o risco é a probabilidade de perda esperada para uma área habitada em um determinado tempo, devido à presença iminente de um perigo (KOBIYAMA et al., 2006).

\section{CONTAMINAÇÃO POR COMBUSTÍVEIS}

O potencial poluidor dos PRC's pode ser exemplificado pelos malefícios que as substâncias comercializadas no mesmo, causam ao meio social e ambiental. Os incômodos causados pelo odor do combustível quando atinge o interior de residências e estabelecimentos comerciais, expõe as pessoas a substâncias tóxicas à saúde humana, como os hidrocarbonetos monoaromáticos, mais conhecidos como Benzeno, Tolueno, Etilbenzeno e Xileno “BTEX” (TROVÃO, 2006). 
Embora não muito comum, também é possível ocorrer a contaminação das redes de abastecimento de água potável por meio da migração de poluentes para o interior das tubulações, e sua distribuição e consumo para parte da população, especialmente nas regiões com déficit hídrico motivado por manutenções na rede ou por sistemas de rodízio em épocas de racionamento (VALENTIN, 2008).

A contaminação de solos e águas subterrâneas causadas pelos postos de serviços é, na grande maioria dos casos, provocada por vazamentos em tanques e tubulações subterrâneas ou constantes e sucessivos extravasamentos junto às bombas e bocais de enchimento (Figura 1). Geralmente os acidentes são percebidos somente após o afloramento do produto em galerias de esgoto, redes de drenagem de águas pluviais, no subsolo, em túneis, escavações e poços de abastecimento d'água (MARANHÃO; TEIXEIRA.C; TEIXEIRA, T., 2007).

Figura 1 - Processo de transporte de combustível no solo.

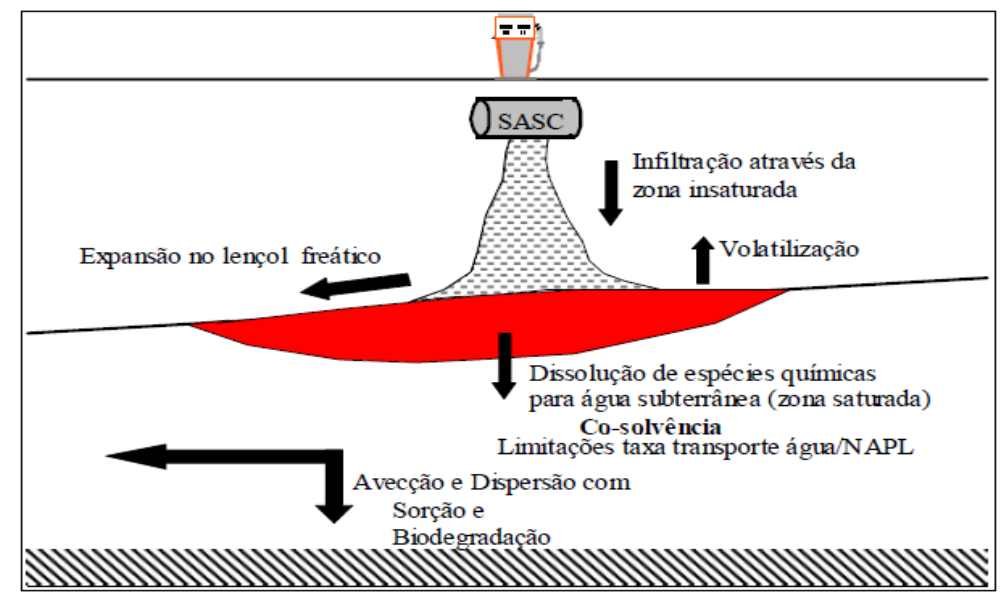

Fonte: Maranhão; Teixeira. C; Teixeira. T (2007).

Após ocorrer um vazamento, ao entrar em contato com o solo, o contaminante infiltra no ambiente e essa infiltração pode ser facilitada conforme a permeabilidade do meio (Figura 2). A permeabilidade é a capacidade que o solo possui de permitir o escoamento de água entre os seus espaços vazios, pode ser medida pelo coeficiente de permeabilidade e influenciada por diversos fatores, tais quais a granulometria, composição mineralógica, índice de vazios, fluído, estrutura, macroestrutura e temperatura do ar (GREGORCZYK; PICCIONI, 2011).

Figura 2 - Contaminação do solo e da água subterrânea.

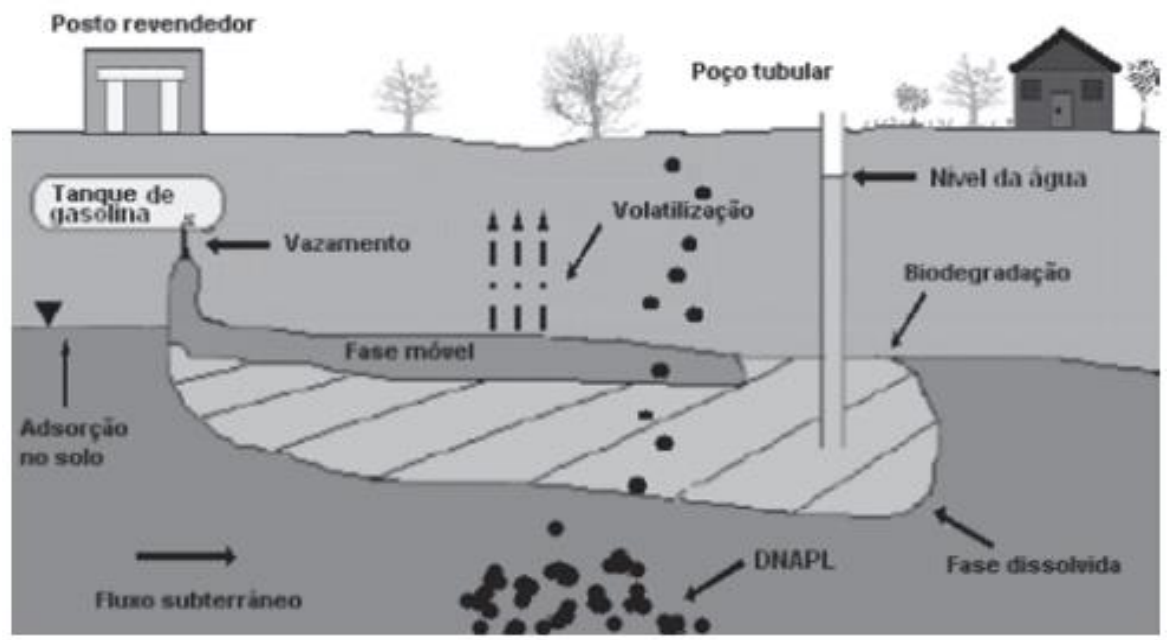

Fonte: Forte et al. (2007). 
As consequências da contaminação são sérios problemas à saúde pública. Os maiores problemas das contaminações por derivados de petróleo são atribuídos aos hidrocarbonetos monoaromáticos (BTEX), que são os constituintes mais solúveis e mais móveis da fração da gasolina, sendo os primeiros a atingir o lençol freático. Estes compostos são depressores do sistema nervoso central, e apresentam toxicidade crônica, mesmo em pequenas concentrações (da ordem de ppb), sendo o benzeno o mais tóxico e comprovadamente carcinogênico (VASCONCELOS et al., 2014).

Desta forma, a contaminação ambiental é considerada crime ambiental pela Lei Federal 9.605:1998, regulamentada pelo Decreto 3.179:1999. A legislação brasileira obriga todos os postos de revenda de combustíveis a serem devidamente licenciados pelos órgãos ambientais competentes após cadastramento do mesmo. A resolução CONAMA n. 273:2000, dispõe que na ocorrência de passivos ambientais, os proprietários, arrendatários ou responsáveis pelo estabelecimento, equipamentos e sistemas além dos fornecedores de combustíveis, responderão solidariamente pela situação, contribuindo para o saneamento das áreas impactadas (BRASIL, 2000).

Portanto, o presente estudo objetivou a verificação dos riscos, perigos e vulnerabilidades proporcionadas ao meio socioambiental pelo PRC, uma vez que a realização do mesmo tem o intuito de despertar a necessidade de maior atenção dos órgãos fiscalizadores, por exemplo, a Secretaria Municipal de Meio Ambiente (SEMMA), e dos empreendedores no que tange à infraestrutura dos postos e, principalmente, a vulnerabilidade ambiental.

\section{MATERIAL E MÉTODOS}

A pesquisa foi efetuada no Núcleo Cidade Nova, bairro Laranjeira, que teve início em 1976, confluência da Avenida Boa Esperança com a Rua Kalil Mutran, no Auto Posto Liz, instalado no ano de 2008 cuja área total equivale a $530 \mathrm{~m}^{2}$, e 349,60 m² de área construída. A localização geográfica é definida pelas coordenadas geográficas: $05^{\circ} 22^{\prime} 40,6^{\prime}$ 'S e $49^{\circ} 07^{\prime} 49,5^{\prime}$ 'W (Figura 4).

Figura 4 - Localização do PRC, Núcleo Cidade Nova. Marabá - PA.

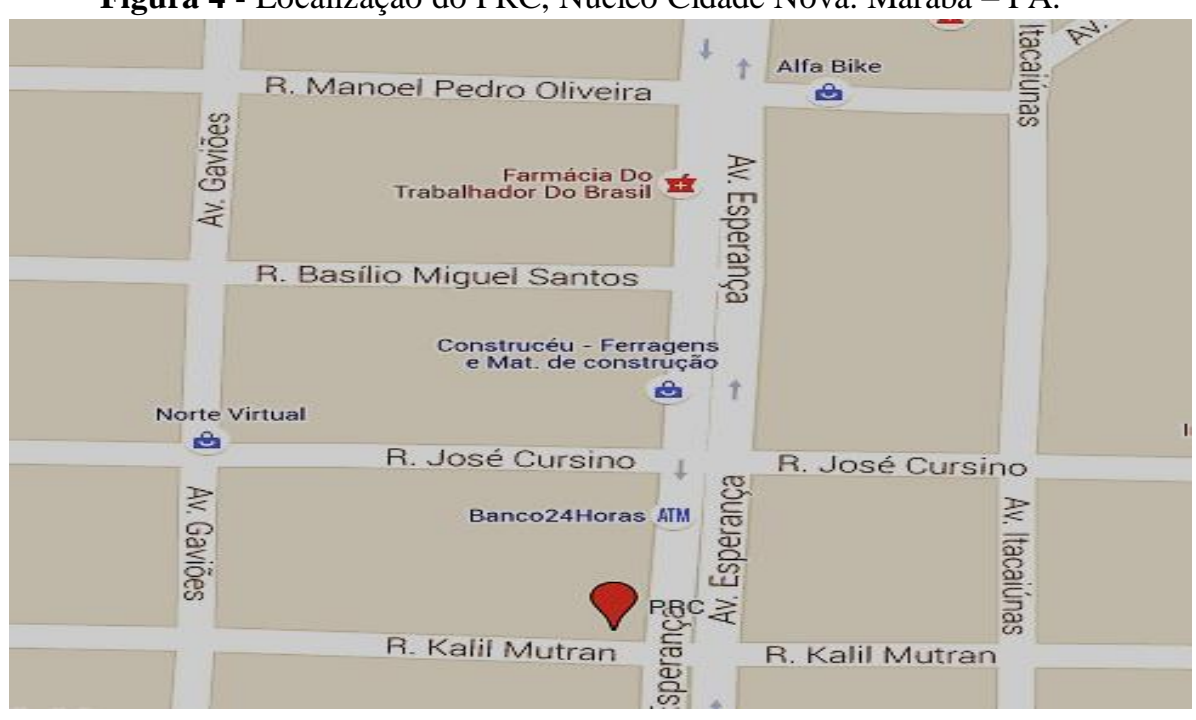

Fonte: autores (2015)

A escolha da área foi definida pelo fato de que o entorno do empreendimento apresenta características que expõe o mesmo a vulnerabilidade, perigo e risco social e ambiental. Como também, ao considerar a insegurança e a exposição a riscos provocadas pelo desempenho das atividades no PRC, e devido à variedade de unidades ocupacionais do solo, que são residências e comércios (Figura 5). 
Figura 5 - Croqui da área. Núcleo Cidade Nova. Marabá - PA.

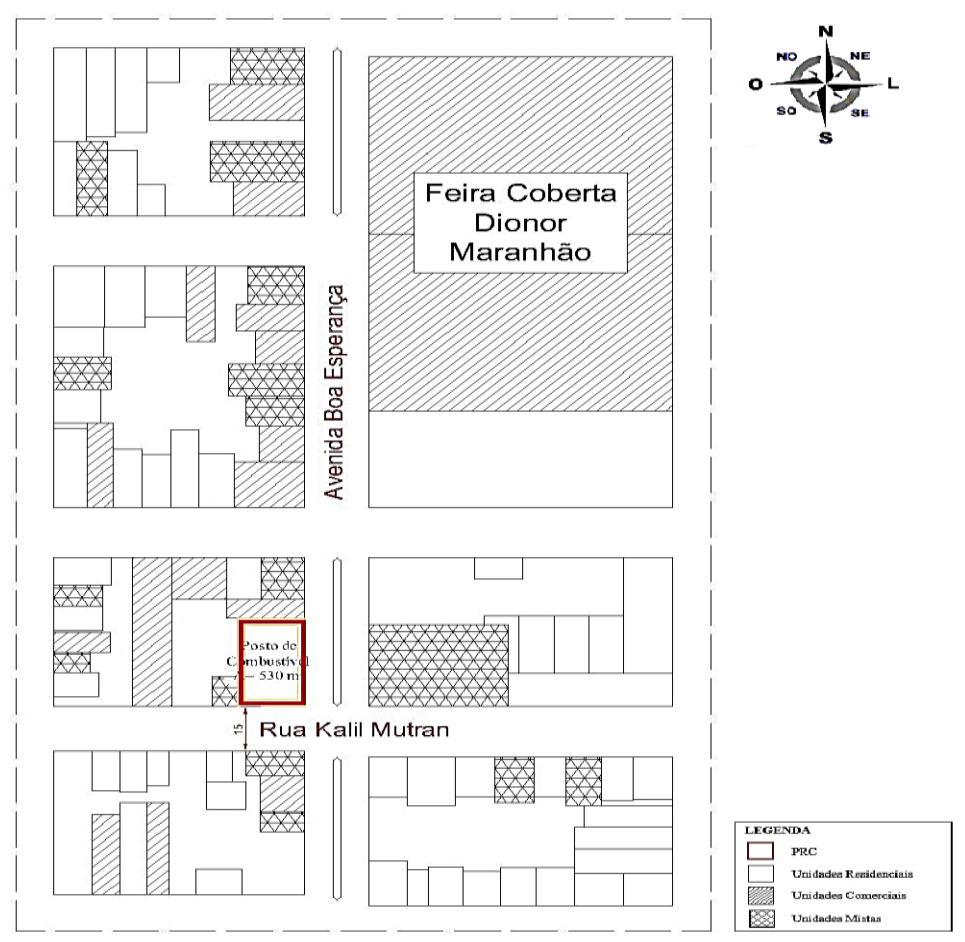

Fonte: autores (2015).

O zoneamento da área de estudo é denominado como Unidade Mista, que é aquele constituído pelos uso-residencial e não-residencial na mesma edificação, ou seja, são unidades mista (MARABÁ, 2006). Residências e comércios constituem essa área compartilhando do mesmo espaço, os estabelecimentos comerciais são diversos: lojas de eletrodomésticos, materiais para construção, barbearia, drogaria e bares. A unidade residencial vizinha ao posto, na rua Kalil Mutran utiliza como limite o muro que divide os terrenos e as paredes para as construções (Figura 6).

Figura 6 - Localização do PRC em Unidade Mista, Núcleo Cidade Nova. Marabá - PA.

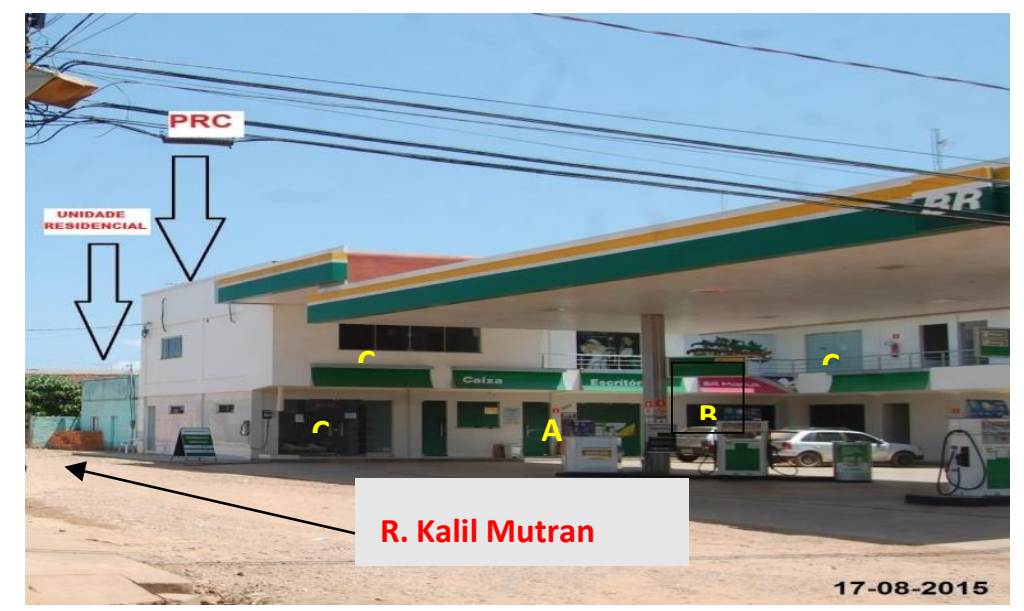

Legendas: A - gerência do posto; B - Loja de conveniências; C - salas para locação.

Fonte: autores (2015).

O PRC tem estrutura ampla, e o abastecimento de combustíveis é realizado por quatro bombas distribuídas na área de servidão. O pátio é revestido de piso polido impermeabilizado e na parte de escritório, além do funcionamento da gerência do posto (A), possui uma loja de conveniência (B) e salas para locação (C) nos dois pavimentos da edificação. Em relação à caracterização da área, 
próximo ao PRC está localizada a feira coberta da Laranjeira, Dionor Maranhão, no sentido nortesul, ao lado oposto da via principal de acesso em relação ao posto de combustível. A distância entre os dois pontos é de aproximadamente 70 metros (Figura 7).

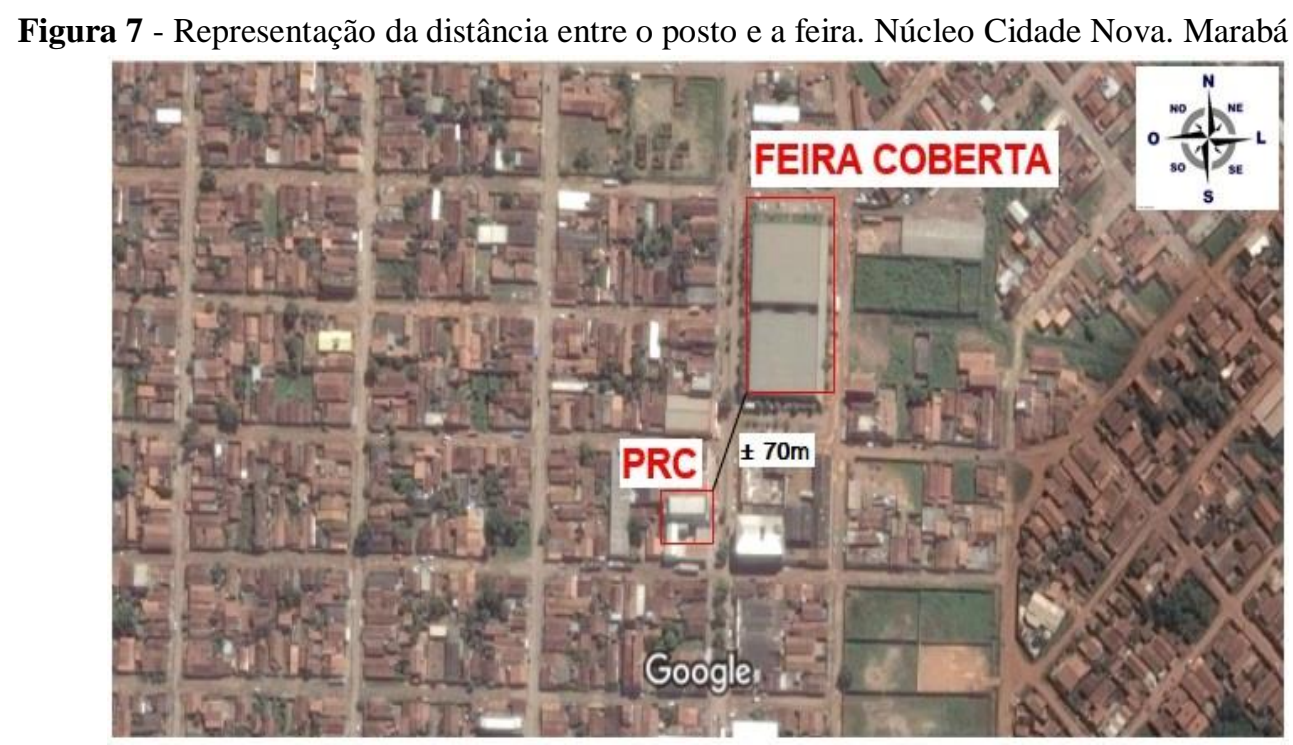

Fonte: autores (2015).

\section{RESULTADOS E DISCUSSÃO}

\section{IMPLANT AÇÃO DO EMPREENDIMENTO}

Os dados obtidos e analisados indicaram que, para a instalação do empreendimento em tela, não houve consulta da opinião popular quanto à instalação do mesmo, logo, não foi levado em conta a opinião (aceitação ou rejeição) que os moradores da área faziam sobre a implantação do empreendimento naquele determinado local.

Acerca desse tipo de pesquisa, foi efetuado um estudo em São Paulo - SP, por Prieto (2006), concluiu que a gestão democrática da cidade, por meio da participação direta da população interessada, é um dos principais objetivos do Estatuto da Cidade. Essa diretriz garante esse princípio democrático também nas questões ambientais, especialmente, nas discussões de projetos e empreendimentos de relevante impacto sobre o meio ambiente e a qualidade de vida da população. Assim, todas as propostas de implantação de grandes empreendimentos ou atividades devem ser discutidas em audiências públicas com a população afetada e interessada, além de serem objeto de análise por meio do EIA e do EIV.

Os fatos verificados no presente estudo, não corroboram com o que foi afirmado pelo autor (PRIETO, 2006), uma vez que não foi efetivada a consulta com a população local quanto à implantação do empreendimento, o que não garantiu o princípio democrático da mesma. Isso resulta em incremento de vulnerabilidade, perigo e riscos ambientais e sociais nesse local.

\section{OBSERVAÇÕES IN LOCO E ENTREVISTA INFORMAL CONTAMINAÇÃO DO SOLO DECORRENTE DE FALHAS NA ESTRUTURA FÍSICA DO PRC.}

Em relação ao piso e ao sistema de drenagem para a caixa Separadora de Água e Óleo (SAO), a análise dos dados obtidos indicou que o PRC tem o piso impermeabilizado e não possui rachaduras. Em relação a presença do piso e sistema de drenagem para esse reservatório, Neves (2010), realizou 
uma pesquisa em São Carlos - SP, foi indicado que o piso da pista de abastecimento deve ser impermeável e toda a área de abastecimento de veículos, inclusive onde os tanques são instalados deve ser construída de concreto usinado. A deterioração existente no piso das pistas de abastecimento, quase sempre, são reflexos do esforço imposto pela circulação de veículos no local. Nestas condições as tubulações e tanques subterrâneos estão sujeitos aos efeitos da vibração e da movimentação do solo, que podem gerar rupturas, principalmente nas conexões. A constituição e condição do piso é um fator importante, pois influencia na infiltração de combustível no solo, decorrente de vazamentos durante as operações de descarregamento ou de abastecimento.

No PRC objeto desse estudo foi verificado que a situação do local atribui ao posto uma característica favorável, uma vez que o piso foi construído de maneira correta evitando com que haja infiltração de contaminantes no solo, como também colabora para a não contaminação do solo e águas subterrâneas. Quanto a presença de canaletas para direcionar os efluentes líquidos para a caixa específica Os dados obtidos indicaram que não há, sobre as mesmas, não possuem grades de proteção, e tais canaletas estão instaladas fora da projeção da cobertura do PRC, logo, não tem caimento apropriado para o local de tratamento.

Em relação a essas canaletas e as proteções com grades, Burjouski (2013), efetuou um estudo na cidade de Campo Mourão - PR, e concluiu que canaleta de contenção deve ser executada sob a projeção da cobertura, uma vez que, a mesma tem função de conter derramamentos sob a pista de abastecimento e também receber os efluentes e direcioná-los para o sistema que separa fisicamente produtos imiscíveis com a água, além da correta instalação da canaleta de contenção instalada sobre o piso com caimento apropriado para o local de tratamento.

Todavia, no empreendimento objeto dessa pesquisa, essas condições não condizem com a situação ideal apresentada em Campo Mourão, pois, as instalações das mesmas não estavam nas condições descritas. Elas, além de estarem obstruídas por resíduos sólidos em alguns pontos, não estavam de forma adequada sob a projeção da cobertura e, dessa forma, direcionavam a água pluvial para a caixa SAO, o que não é correto. Também não possuem grades de proteção, o que deixa a área propensa a acidentes envolvendo motocicletas porque o pneu por ser estreito, pode entrar na canaleta e ficar preso nela. Além do mais, a ausência do caimento apropriado, possibilita a contaminação a todo instante.

\section{VERIFICAÇÕES}

\section{CONTAMINAÇÃO DAS FONTES DE ABASTECIMENTO DE ÁGUA}

Em relação ao processo de abastecimento de água, dos moradores da Rua Kalil Mutran, localizada na lateral esquerda do posto, a partir da Avenida Boa Esperança e com o observador de frente ao mesmo (Figura 8), os resultados mostraram que esse abastecimento é efetuado com o uso de água proveniente de poço do tipo amazonas (cacimba) e da rede pública Companhia de Saneamento do Pará (COSANPA). 
Figura 8 - Rua Kalil Mutran. Núcleo Cidade Nova. Marabá - PA.

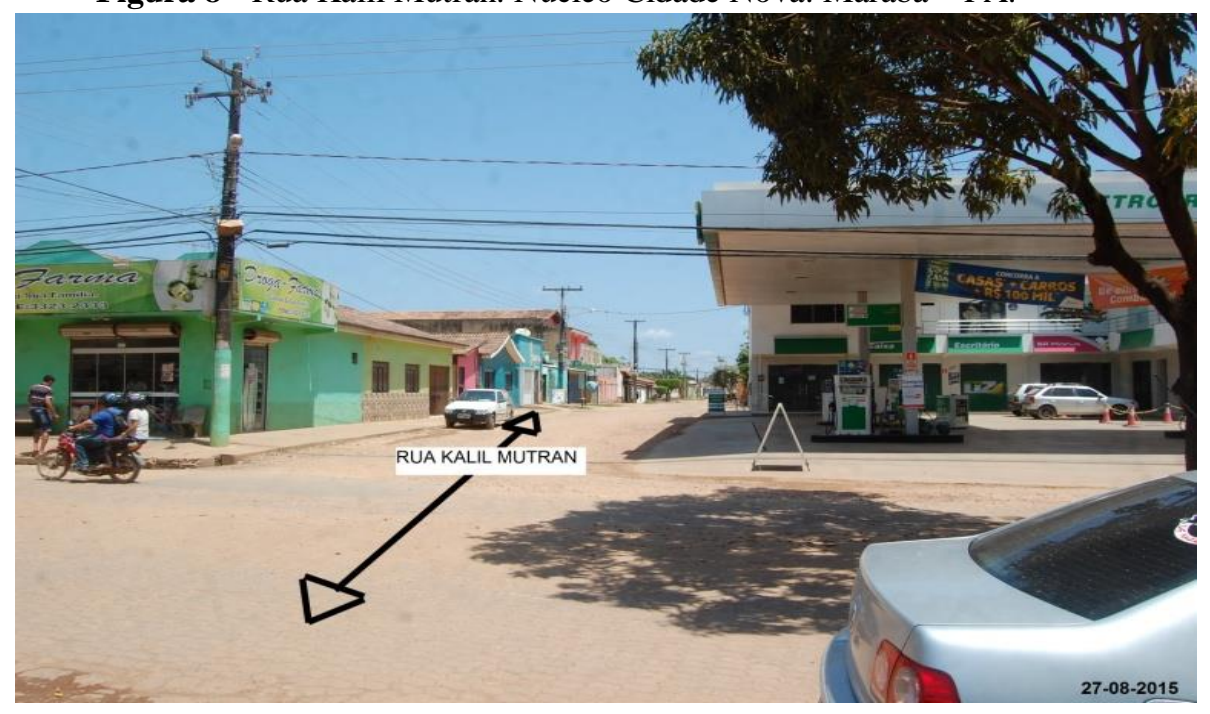

Fonte: autores (2015).

Acerca desse tema, Forte et al. (2007), efetuaram estudo em Porto Velho - RO, e concluiram que os poços escavados do tipo "Amazonas" são as fontes de água da maioria da população, e nem sempre são construídos obedecendo a critérios técnicos, tornando a população usuária deste tipo de abastecimento vulnerável aos riscos de consumir água contaminada por combustíveis provenientes de vazamentos de tanques de armazenamento subterrâneos dos postos revendedores e distribuidoras, além de outros contaminantes.

Esses vazamentos podem acarretar sérios impactos ambientais devido à contaminação do solo e das águas subterrâneas, comprometendo a qualidade dos recursos hídricos e seu uso para abastecimento. No presente estudo foi verificado que, quanto ao risco de ocorrência de estanque nos tanques de armazenamento de combustíveis do PRC, poderá ocorrer contaminação do lençol freático, o que prejudicará a qualidade da água utilizada pela circunvizinhança. Contudo, para que isso aconteça, há dependência da direção da pluma. Isso corrobora com os aspectos expostos no estudo realizado em Rondônia. Outra via de contaminação das águas pode ocorrer em caso de ruptura nas luvas da rede de abastecimento, o contaminante pode adentrar as tubulações e comprometer a qualidade da água que chega à encanação das residências.

\section{RISCOS SOCIOAMBIENTAIS}

Com os dados obtidos e analisados, observou-se que a população se sente vulnerável a ocorrência de assaltos e acidentes envolvendo automóveis ou a rede de energia elétrica com o PRC. Porém, não há preocupação quanto ao risco de ocorrer explosões seguidos de incêndios em decorrência de vazamentos e derreamentos possíveis de acontecer. Na pesquisa realizada em Francisco Beltrão -PR, por Palavecini et al. (2012) os dados obtidos indicaram que a potencial capacidade de gerar acidentes ambientais é justificada pelo fato de que todo vazamento de combustível pode contaminar corpos d'água subterrâneos ou superficiais, o solo e o ar, além dos riscos de incêndio e explosões decorrentes dos vazamentos. Nesses empreendimentos, os acidentes ambientais e vazamentos vêm aumentando principalmente por falta de manutenção adequada ou manutenção insuficiente, sistemas e equipamentos obsoletos, falta de treinamento aos empregados, ausência de sistemas adequados para detectar vazamentos e a insuficiente capacidade de reação aos acidentes ambientais.

Em caso de acidente no PRC, todos os que estiverem presente no entorno não saberão a maneira correta de como reagir a tal fato, evidenciando a falta de organização e responsabilidade 
por parte dos proprietários em relação ao planejamento das ações a serem desencadeadas em situações emergenciais, pois é de grande relevância para a minimização dos danos, para a saúde humana e meio ambiente. O tempo de resposta, a eficiência das ações empregadas, a magnitude dos danos evitados e a disponibilidade dos recursos necessários são alguns dos parâmetros importantes para a avaliação da eficácia de um atendimento emergencial.

Conforme dados relatados pelos funcionários do PRC, o serviço desempenhado por eles são os de abastecimento de automóveis e a revenda de óleo lubrificante, não efetuando a troca no local. E que ao longo da jornada de trabalho ou após o expediente eles sentem enjoos e dores de cabeça. A exposição aguda ao tolueno decorrente da inalação pode causar fadiga, sonolência, dores de cabeça, náusea, confusão e falta de apetite. Esses sintomas geralmente desaparecem quando a exposição é interrompida. A inalação em níveis elevados em períodos curtos pode causar tonteira ou sonolência. Pode também causar perda da consciência e mesmo a morte. Níveis elevados podem também afetar os rins (BRASIL, 2010).

O mal-estar relatado por eles se deve a exposição direta a qual estão sujeitos, seja através dos vapores que podem ser inalados ou mesmo pelo contato direto. Assim como é consequência da intoxicação causada pelo Tolueno, utilizado como mistura presente na gasolina, a substância adentra as vias respiratórias e causa irritação, o que pode ser agravado durante o horário de pico de energia solar que se estende das $11 \mathrm{~h} 00$ minutos às $14 \mathrm{~h} 00$ minutos.

\section{PERCEPÇÃO AMBIENTAL DA COMUNIDADE DO ENTORNO AO PERÍGO DO PRC.}

Os dados obtidos e analisados indicaram, quanto amostragem populacional envolvida nessa pesquisa, um total de 89 indivíduos, dos quais, 35 são moradores da área, 50 trabalham na área e residem em outro local e quatro são funcionários do PRC (Figura 9).

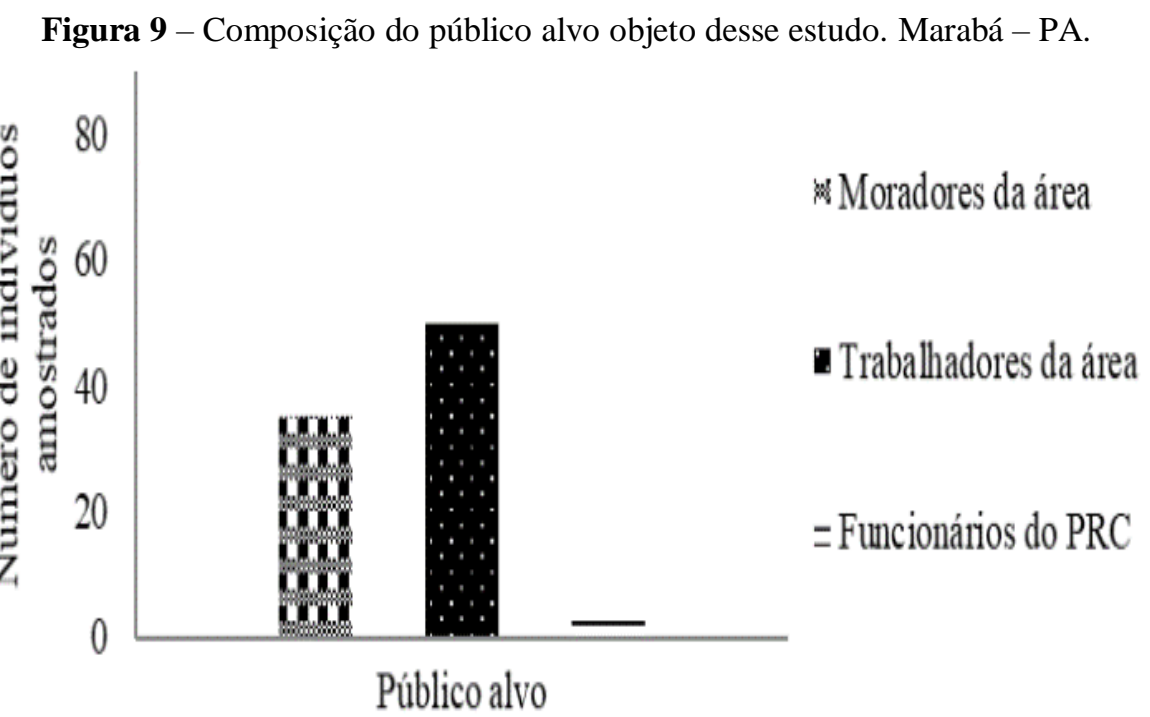

Fonte: autores (2015).

Em relação aos riscos ambientais associados ao PRC como, contaminação do solo, contaminação da água, incêndio ou explosão, ou ainda a não associam riscos ao empreendimento, 20 deles (16 trabalhadores da área; quatro moradores da mesma) foram enfáticos em afirmar de que não tem como associar a presença do posto revendedor de combustível com algum tipo de risco (Figura $10)$. 
Figura 10 - Riscos ambientais associados ao PRC. Marabá - PA.

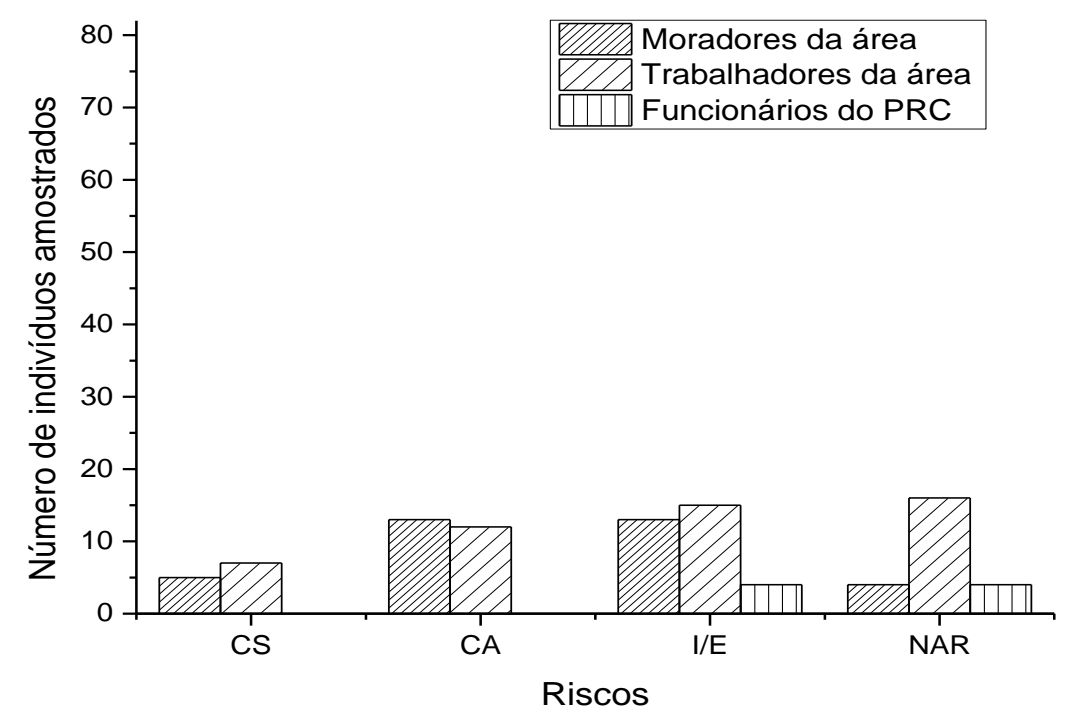

Legendas: CS - Contaminação do Solo; CA- Contaminação da água. I/E - Incêndios/explosões; NAR Nenhum Risco Associado

Fonte: autores (2015).

A análise dos dados indicou também que, em relação a contaminação do solo, dos 89 indivíduos amostrados, apenas $12(13,48 \%)$ dos moradores da área onde se localiza o empreendimento, temem um vazamento de combustível. Esse mesmo temor é compartilhado por 12 (14\%) trabalhadores do entorno do PRC. Tais valores apresentam tendência de incremento quando se trata da contaminação da água, pois, 33 (37\%) dos moradores da área relataram tal preocupação, que é compartilhado com 21 (23,59\%). Acerca desse temor, em uma pesquisa pioneira realizada por Oliveira e Loureiro (1998) em Belo Horizonte - MG, os dados obtidos indicaram que, das possíveis fontes de extravasamento de petróleo no meio ambiente, os postos revendedores de combustíveis são os que mais preocupam, devido à dispersão deles e o volume de derivados de petróleo que armazenam. Logo, o temor dos 54 indivíduos amostrados no município de Marabá, deve ser aceito como um alerta às autoridades ambientais e de saúde.

Quanto ao principal risco associado ao PRC, ou seja, incêndio ou explosão, os d ados obtidos a analisados indicaram que ambos os riscos são temidos pelos três grupos: moradores da área (33= $37 \%)$; trabalhadores da área do entorno $(27=30 \%)$ e que compõe o público entrevistado na pesquisa, sendo 37\% dos moradores, 30\% trabalhadores da área e 100 funcionários do PRC. Com relação á não associar risco, que foi a última resposta, onde 20 entrevistados, dentre estes 4 moradores da área e 16 trabalhadores da área, que resultam em 11,5\% dos moradores da área entrevistados e 32\% dos que trabalham no entorno, não associam nenhum risco ao posto. Pois as respostas são embasadas na falta de conhecimento da população, em relação aos riscos que o PRC oferece. Em sua maioria, a população agrega a possibilidade de explosão e incêndio ao manuseio de material inflamável e desconhecem as demais formas de ocorrer tal fato.

Na cidade de Guarulhos - SP, Gouveia e Nardocci (2007), efetuaram estudo acerca dos riscos que um PRC oferta, e concluiram que os acidentes em postos e sistemas retalhistas de combustíveis normalmente estão localizados em área urbana onde o subsolo é entrecortado de galerias com redes de diversos serviços públicos. Os produtos comercializados como gasolina e álcool são inflamáveis e voláteis e quando liberados podem resultar em incêndios e explosões, com danos graves imediatos à vida e saúde das pessoas. Esses cenários resultam ainda em contaminação do solo e água, e na exposição de pessoas aos vapores tóxicos. A presença do odor característico é também agravante, pois gera pânico na população e, em alguns casos, estresse a ponto de aumentar o registro de queixas de problema de saúde. 
Vazamentos em postos de combustíveis provocam grandes problemas ao meio ambiente, principalmente no que diz respeito a contaminação do solo e de águas subterrâneas. Porém, a maioria das pessoas desconhecem essas consequências, talvez por falta de conhecimento, como foi relatado por alguns e isso faz com que ao estarem expostas à água contaminada, via rede de abastecimento público ou de poços freáticos, por desconhecerem a vulnerabilidade a que estão sujeitos, não notem logo que ocorrer, e isto resultara em agravamento das consequências.

Os contaminantes BTEX são frequentemente encontrados em águas subterrâneas. Em função de muitos tanques terem muitos anos de uso, por isso a possibilidade de ocorrerem vazamentos é extremamente grande, principalmente pelo surgimento de rachaduras ou corrosão. As consequências dos vazamentos de combustíveis automotivos em postos estão associadas à possibilidade de incêndios e explosões, assim os danos imediatos à vida humana são graves, uma vez que é passivo de ocorrer a qualquer momento caso o empreendimento esteja operando com falhas.

\section{CONCLUSÃO}

O PRC oferece vulnerabilidade, risco e perigo á circunvizinhança do entorno do empreendimento, bem como aos funcionários do posto. $\mathrm{O}$ risco proporcionado ao meio socioambiental, é em decorrência da possibilidade vazamentos nos tanques de abastecimento que, ao ocorrer, contaminará o solo e a água subterrânea, ou até mesmo a rede de abastecimento pública. Os riscos socioambientais, se mostraram mais significativos e evidentes. O medo de assaltos, é um impacto social negativo resultante do funcionamento do posto, e é o mais ressaltado pela população.

A população desconhece os riscos e vulnerabilidades a que estão expostas, em virtude da instalação e funcionamento do posto, em função disto ela associa riscos, que na prática não são tão significantes, por ser rara a ocorrência dos mesmos. Bem como não há informação por parte dos mesmo sobre o Plano de Emergência do empreendimento na ocorrência de situações emergenciais.

Por fim, a localização do posto em locais de unidades de ocupação diversificadas, influencia na quantidade de pessoas expostas a riscos e vulnerabilidade. O ideal é que estes se localizem em lugares de fluxo reduzido de pessoas. A fim de enriquecimento da pesquisa, é necessária uma maior atenção quanto a este assunto, a partir do desenvolvimento de mais trabalhos nesta linha de pesquisa.

\section{REFERÊNCIAS}

ADGER, W. N. Vulnerability. Global Environmental Change, Reino Unido, v. 16, p. 268-281, 2006.

ABNT. ASSOCIAÇÃO BRASILEIRA DE NORMAS TÉCNICAS. NBR 13786: Posto de serviço - Seleção dos equipamentos para sistemas para instalações subterrâneas de combustíveis. Rio de Janeiro, jun. 2005.

BRASIL. AGÊNCIA NACIONAL DO PETRÓLEO. Resolução nº 41, de 05 de novembro de 2013. Regulamenta o exercício da atividade de revenda varejista de combustível automotivo. Diário Oficial da República Federativa do Brasil, Brasília, DF, 06 nov. 2013.

BRASIL. CONSELHO NACIONAL DO MEIO AMBIENTE. Resolução ${ }^{\circ}$ 273, de 29 de novembro de 2000. Dispõe sobre Prevenção e Controle da Poluição em Postos de Combustíveis e Serviços. Diário Oficial da República Federativa do Brasil, Brasília, DF, 08 jan. 2001.

BRASIL. CONSELHO NACIONAL DO MEIO AMBIENTE. Resolução no 357, de 17 de março de 2005. Dispõe sobre a Classificação dos corpos de Água e Diretrizes Ambientais para o seu enquadramento. Diário Oficial da República Federativa do Brasil, Brasília, DF, 18 mar. 2005. 
BRASIL. Lei $\mathrm{n}^{\circ}$. 6.938 de 31 de agosto de 1981. Institui a Política Nacional do Meio Ambiente. Diário Oficial da República Federativa do Brasil, Brasília, DF, 02 set. 1981.

BRASIL. MINISTÉRIO DA SAÚDE. Vigilância do câncer ocupacional e ambiental. Rio de Janeiro: INSTITUTO NACIONAL DO CANCER (INCA), 2010.

BRASIL. Lei n ${ }^{\circ} 10.257$ de 10 de julho 2001. Lei do Estatuto da Cidade. Diário Oficial da República Federativa do Brasil, Brasília, DF, 11 jul. 2001.

BRITO JÚNIOR, A. F.; FERES JÚNIOR, N. A utilização da técnica da entrevista em trabalhos científicos. Evidência, Araxá, MG, v. 7, n. 7, p. 237-250, 2011.

BURKOUSKI, P. Estudo De Caso: Readequação E Reforma De Um Posto Revendedor Retalhista De Combustível Automotivo. Campo Mourão (PR). 2013. Trabalho de Conclusão de Curso (Graduação em Tecnólogo em Materiais de Construção Civil) - Universidade Tecnológica Federal do Paraná, Campo Mourão, 2013.

CETESB. Companhia de Tecnologia de Saneamento Ambiental do Estado de São Paulo. 2011. Norma Técnica - P4.261 - Risco de Acidente de Origem Tecnológica - Método para decisão e termos de referência. Disponível em $<$ http://www.cetesb.sp.gov.br/wpcontent/uploads/sites/11/2013/11/P4261-revisada.pdf >. Acesso em: 05 nov. 2015.

COUTINHO, R. C. P.; GOMES, C. C. Técnicas para Remediação de Aquíferos Contaminados por Vazamentos de Derivados de Petróleo em Postos de Combustíveis. In: Simpósio Brasileiro de Recursos Hídricos, 27. 2007, São Paulo. Anais... São Paulo: Associação Brasileira de Recursos Hídricos, 2007. p. 2.

CUNHA, I. A. Gerenciamento de Riscos Ambientais e a Política de Proteção dos Mananciais em São Paulo. INTERFACEHS- Revista de Gestão Integrada em Saúde e Meio Ambiente, São Paulo, v.3, n. 3, Artigo 4, 2008. Disponível em < www.interfacehs.sp.senac.br>. Acesso em: 09 dez. 2015.

CUTTER, S. L. A ciência da vulnerabilidade: modelos, métodos e indicadores. Revista Crítica de \begin{tabular}{lll|llll} 
Ciências & Sociais & [online], & 93 & 2011. & Disponível
\end{tabular} <http://rccs.revues.org/165;DOI:10.4000/rccs.165>. Acesso em: 15 nov. 2015.

DAGNINO, R. S.; CARPI JUNIOR, S. Risco ambiental: conceitos e aplicações. Climatologia e Estudos da Paisagem, Rio Claro, v. 2, n. 2, p. 50-87, 2007.

FARIAS, D. O. Avaliação Quantitativa de Risco de uma Refinaria de Petróleo. Recife. 2010. Dissertação (Mestrado em Engenharia da Produção) - Universidade Federal do Pernambuco, Recife, 2010.

FORTE, E. J. Contaminação de Aquífero por Hidrocarbonetos: Estudo de Caso na Vila Tupi, Porto Velho- Rondônia. Quím. Nova (online), v. 30, No. 7, 1359-1544, 2007. Disponível em http://quimicanova.sbq.org.br/detalhe_artigo.asp?id=1675. Acesso em: 05 nov. 2015.

GALLOPIN, G. C. Linkages between vulnerability, resilience, and adaptive capacity. Global Environmental Change, Santiago, v. 16, n.3, p. 293-303, 2006. 
GREGORCZYK, G; PICCIONI, W. J. Analise da Eficiência da Remediação por Sistema Extração multifásica em Postos de Combustíveis. 2011. Trabalho de Conclusão de Curso (Graduação). Universidade Tecnológica Federal do Paraná, Curitiba, 2011.

GOUVEIA, J. L. N.; NARDOCCI, A. C. Acidentes em Postos e Sistemas Retalhistas de Combustíveis: Subsídios para a Vigilância em Saúde Ambiental. Engenharia Sanitária e Ambiental, v. 12, n. 3, 317-324, 2007.

HOUAISS. Dicionário Houaiss da Língua Portuguesa. Rio de Janeiro: Objetiva, 2001.

IBAMA. INSTITUTO BRASILEIRO DO MEIO AMBIENTE E DOS RECURSOS NATURAIS RENOVÁVEIS. Termo de Referência para o Licenciamento de Postos de Abastecimento em Operação. Brasília, 2007.

IELO, E. M.; ZACHARIAS, A. A. Avaliação das Áreas de Risco como Subsídio ao Planejamento Urbano. In: Congresso Brasileiro de Cartografia, 27. 2014. Gramado- RS. Anais... Gramado: Sociedade Brasileira de Cartografia, Geodesia, Fotogrametria e Sensoriamento Remoto, 2014.

ISO. INTERNATIONAL ORGANIZATION FOR STANDARDIZATION. Environmental management systems - Requirements with guidance for use, ISO 14001. Genebra, 2004.

JANCZURA, R. Risco ou vulnerabilidade social. Textos \& Contextos. Porto Alegre, RS, v. 11, n. 2, p. 301-308, 2012.

KOBIYAMA, M. et al., Prevenção de Desastres Naturais: Conceitos Básicos. Curitiba: Organic Trading, 2006.

LIMA, D. O.; COSTA JÚNIOR, F. A.; BACELAR NETO, N. Análise de exposição a riscos dos frentistas em postos revendedores de combustíveis na cidade de Salvador. 2008. Monografia (Especialização em Engenharia de Segurança do trabalho). Escola Politécnica, Universidade Federal da Bahia, Salvador, 2008.

MARABÁ. Lei $\mathbf{n}^{\circ} \mathbf{1 7 . 2 1 3}$ de 09 de outubro de 2006. Institui o Plano Diretor Participativo do Município de Marabá, cria o Conselho Gestor do Plano Diretor e dá outras providencias. Marabá, 09 out. 2006.

MARANDOLA JÚNIOR. E.; HOGAN, D. J. As dimensões da Vulnerabilidade. São Paulo em Perspectiva, São Paulo, v. 20, n. 1, p. 33-43, 2006a.

MARANDOLA JÚNIOR, E.; HOGAN, D. J. Vulnerabilities and risks in population and environment studies. Population and Environment, New York, v.28, 2006 b.

MARANHÃO, D. TEIXEIRA, C. A.; TEIXEIRA, T. M. A. Procedimentos de Investigação e Avaliação da Contaminação em Postos de Combustíveis, Utilizando Metodologias de Análise de Risco: Aplicação da ACBR em Estudo de Caso na RMS. 2007. Monografia (Especialização em Gerenciamento de Tecnologias Ambientais e Tecnologias) - Universidade Federal da Bahia, Salvador, 2007.

MARIANO, A. P. Avaliação do Potencial de Biorremediação de Solos e de Águas Subterrâneas Contaminados com Óleo Diesel. Rio Claro (SP). 2006. Tese (Doutorado em Geociências e Meio Ambiente) - Universidade Estadual Paulista, Rio Claro, 2006 
NEVES, A. A. C. Estudo sobre resíduos sólidos em postos de combustíveis, funilarias e estabelecimentos de lavagem automotiva no município de São Carlos, visando indicadores de sustentabilidade. São Carlos. 2012. Tese (Doutorado em Ciências da Engenharia Ambiental) Universidade de São Paulo, São Carlos, 2010.

PALAVECINI, A. C. et al., Sistema de gestão Ambiental Simplificado: Um Estudo de Caso no Posto Modelo da Cidade de Francisco Beltrão- PR. In: Congresso Nacional de Pesquisa em Ciências Sociais e Aplicadas, 1. 2012. Francisco Beltrão- PR. Anais... Francisco Beltrão: UNIOESTE, 2012. p. 7.

PAUlinO, E. T. Estudo De Impacto De Vizinhança: Alguns apontamentos a partir do caso de Londrina-PR. Presidente Prudente (SP). Caderno Prudentino de Geografia, v. 2, n. 33, p. 146- 169, 2011. Disponível em: < http://revista.fct.unesp.br/index.php/cpg/article/viewFile/1931/1811>. Acesso em: 20 nov. 2015

PELLETIER, P. Um Japão sem riscos? In: VEYRET, Y. (Org.) Os Riscos: o Homem como agressor e vítima do meio ambiente. São Paulo: Contexto, 2007. p. 201-220.

PRIETO, E. C. O Estatuto da Cidade e o Meio Ambiente. In: IV Congresso Brasileiro de Direito Urbanístico, 4. 2006. Anais... São Paulo: Faculdade de Direito de São Paulo (USP) e Pontífice Universidade Católica (PUC/SP) 2006.

RESCHKE, K. S. S. Estudos Microbiológicos Para Tratamento de Água Subterrânea de Áreas Contaminadas por Hidrocarbonetos. São Leopoldo. 2009. Dissertação (Mestrado em Engenharia Civil) - Universidade do Vale do Rio dos Sinos- UNISINOS. São Leopoldo, 2012.

RIBEIRO, E. A. A perspectiva da entrevista na investigação qualitativa. Evidência. Araxá, MG, n. 04, p.129-148, 2008.

RICHARDSON, R. J. Pesquisa social: métodos e técnicas. 3. ed. 9. Reimpressão. São Paulo: Atlas, 2008.

RIELLI, G. Análise preliminar de risco em postos revendedores de combustíveis da cidade de Curitiba. Curitiba (PR). 2007. Monografia (Graduação em Engenharia Ambiental) -Pontifícia Universidade Católica do Paraná, Curitiba, 2007;

ROSA, M. V. F. P. C.; ARNOLDI, M. A. G. C. A entrevista na pesquisa qualitativa: mecanismos para a validação dos resultados. Belo Horizonte: Autêntica, 2006.

SANTOS, G. L. G. Desenvolvimento e aplicação de método de dessorção química para determinação de BTEX em ar ambiente de postos de combustíveis utilizando cromatografia a gás. 2014. Tese (Doutorado em Química) - Universidade Federal da Bahia, Salvador, 2014.

SANTOS, R. J. S. A Gestão Ambiental em Posto Revendedor de Combustíveis como Instrumento de Prevenção de Passivos Ambientais. 2005. Dissertação (Mestrado em Sistemas De Gestão) - Universidade Federal Fluminense, Niterói, 2005.

SOUZA, C. P. Avaliação e Valoração dos Impactos Ambientais no Processo de Operação de Postos Revendedores de Combustíveis. 2009. Dissertação (Mestrado em Ciências) - Universidade Federal do Rio de Janeiro, Rio de Janeiro, 2009. 
SOUZA, D. C. Breves Considerações Sobre o Licenciamento Ambiental. Revista Jurídica da UniFil, Ano VI, n. 6, 15 p, 2009.

SOUZA, D. C.; CARDOSO, S. L. M. Estudo Prévio de Impacto Ambiental. Maringá (PR). Revista de Ciências Jurídicas, v.7 n.1, p. 43-65, 2009.

TRENNEPOHL, C.; TRENNEPOHL, T. Licenciamento Ambiental. Niterói: Impetus, 2007.

TROVÃO, R. S. Analise Ambiental de Solos e Águas Subterrâneas Contaminadas com Gasolina: Estudo de Caso no Município de Guarulhos- SP. São Paulo, 2006. 224 f. Dissertação (Mestrado em Engenharia) - Escola Politécnica da Universidade de São Paulo, São Paulo, 2006.

VALENTIN, C. A. Estudo da degradação de Geomembrana de Polietileno de Alta Densidade de 2,5 m de espessura frente à Gasolina, Óleo Diesel e Álcool combustível. São Carlos (SP). 2008. Dissertação (Mestrado em Ciências). Instituto de Química da São Carlos. Universidade de São Paulo, São Carlos, 2008

VASCONCELOS, B. S. Áreas Contaminadas por Postos de Combustíveis e Medidas de Remediação no Município de São Bernardo do Campo. Saúde e Meio Ambiente, Mafra, v. 3, n. 1, p. 73-83, 2014.

VENANCIO, T. L.; VIDAL, C. M. de S. e MOISA, R. E. Avaliação da percepção da importância da gestão ambiental em postos de combustíveis localizados na cidade de Irati. Ambiência- Revista do Setor de Ciências Agrárias e Ambientais, Guarapuava, PR, v. 4, n. 3, p. 397-417, 2008.

VEYRET, Y.; MESCHINET DE RICHEMOND, N. O risco, os riscos. In: VEYRET, Y. (Org.) Os Riscos: O Homem Como Agressor e Vítima do Meio Ambiente. São Paulo: Contexto, 2007. p. 23 79.

VIEIRA, A. B. Estudo de Impacto de Vizinhança. Caxias do Sul (RS). Revista Direito Ambiental e Sociedade, v. 2, n. 1, p. 347-360, 2012.

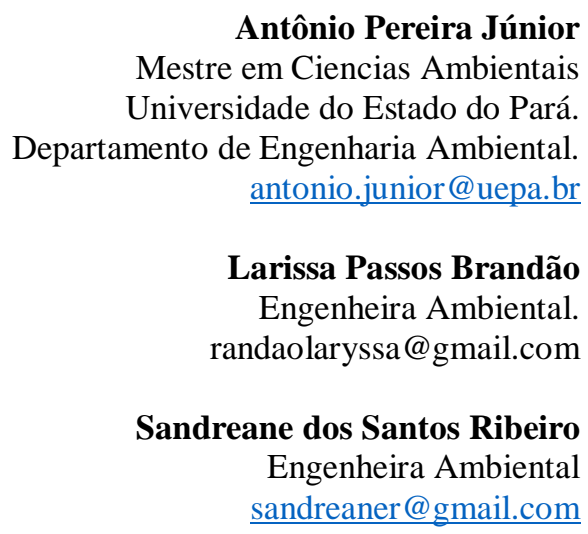

